\title{
Development of a SWAT model in the Yarra River catchment
}

\author{
$\underline{\text { S.K. Das }}^{\mathrm{a}}$, A.W.M. Ng ${ }^{\mathrm{a}}$ and B.J.C. Perera ${ }^{\mathrm{a}}$ \\ ${ }^{a}$ College of Engineering and Science, Victoria University, Melbourne 14428, Australia \\ Email: sushilkumar.das@live.vu.edu.au
}

\begin{abstract}
The degradation of river water quality in Victorian agricultural catchments is of concern. Physics-based models are useful analysis tools to understand diffuse pollution and find solutions through best management practices. However, because of high data requirements and processing, use of these models is limited in many data-poor catchments; for example the Australian catchments where water quality and land use management data are very sparse. Recently, with the advent of computationally efficient computers and GIS software, physics-based models are increasingly being called upon in data-poor regions. SWAT is a promising model for long-term continuous simulations in predominantly agricultural catchments. Limited application of SWAT has been found in Australia for modeling hydrology only. Adoption of SWAT as a tool for predicting land use change impacts on water quality in the Yarra River catchment, Victoria (Australia) is currently being considered. The objective of this paper is to evaluate hydrological behaviour of SWAT model in the agricultural part of the Yarra River catchment for 1990-2008 periods.
\end{abstract}

The SWAT model requires the following data: digital elevation model (DEM), land use, soil, land use management and daily climate data for driving the model, and streamflow and water quality data for calibrating the model. All these data were collected from local organizations except DEM. Water quality and land use management data were most sparse. All input files for the model were organized and assembled following the guidelines of ArcSWAT interface of the SWAT 2005 version. The study area was delineated into 51 sub-catchments and 431 hydrological response units (HRU), which are unique combinations of land use, soil type and slope. The main methods used in modeling the hydrologic processes were curve number method for runoff estimating, Penman-Monteith method for PET and Muskingum method for channel routing.

SWAT embedded sensitivity and auto-calibration tool was used for sensitivity analysis and calibration. The LH-OAT (Latin-Hypercube and One-factor-At-a-Time) sensitivity analysis method was implemented for all 26 SWAT streamflow parameters. Then the ParaSol (SCE-UA) auto-calibration was performed on 14 most sensitive streamflow parameters. The calibration period 1990-2002 includes both wet and dry period, but the validation period 2003-2008 includes only dry period. Since, a bad representation of baseflow and surface runoff can cause wrong estimates of diffuse pollution loads to the river, baseflow $\left(\mathrm{Q}_{\mathrm{bf}}\right)$ and runoff $\left(\mathrm{Q}_{\mathrm{r}}\right)$ were also calibrated along with the total flow $\left(\mathrm{Q}_{\mathrm{t}}\right)$. For runoff and baseflow calibration, manual tuning was done to the baseflow and runoff related parameters. The SWAT model calibration and validation results were evaluated based on the standard guidelines and using the evaluation statistics of Coefficient of Determination $\left(\mathrm{R}^{2}\right)$, Nash-Sutcliffe Efficiency (NSE), Percent Bias (PBIAS) and RMSE-observations standard deviation ratio (RSR). In the calibration period, the respective daily, monthly and annual values of the evaluation statistics were for;

- $\mathrm{Q}_{\mathrm{t}} \rightarrow \mathrm{R}^{2}: 0.78,0.93,0.96$; NSE: 0.77, 0.89, 0.87; PBIAS: 10, 10, 10 and RSR: $0.48,0.34,0.36$

- $\mathrm{Q}_{\mathrm{bf}} \rightarrow \mathrm{R}^{2}: 0.90,0.93,0.95$; NSE: 0.87, 0.89, 0.88; PBIAS: 6, 6, 6 and RSR: 0.36, 0.33, 0.35

- $\mathrm{Q}_{\mathrm{r}} \rightarrow \mathrm{R}^{2}:$ 0.50, 0.84, 0.97; NSE: 0.42, 0.80, 0.76; PBIAS: 23, 23, 23 and RSR: 0.76, 0.45, 0.49

In the validation period, the respective daily, monthly and annual values of the evaluation statistics were for;

- $\mathrm{Q}_{\mathrm{t}} \rightarrow \mathrm{R}^{2}:$ 0.74, 0.82, 0.87; NSE: 0.72, 0.82, 0.81; PBIAS: $-3,-3,-3$ and RSR: 0.53, 0.43, 0.43

- $\mathrm{Q}_{\mathrm{bf}} \rightarrow \mathrm{R}^{2}: 0.79,0.81,0.84$; NSE: 0.77, 0.79,0.71; PBIAS: $-11,-11,-11$ and RSR: 0.48, 0.46, 0.54

- $\mathrm{Q}_{\mathrm{r}} \rightarrow \mathrm{R}^{2}: 0.67,0.82,0.87$; NSE: 0.53, 0.79, 0.70; PBIAS: 19, 19, 19 and RSR: 0.69, 0.46, 0.55

The model performance statistics showed that the SWAT model performed very well for $\mathrm{Q}_{t}$, well for $\mathrm{Q}_{\mathrm{bf}}$ and satisfactory for $\mathrm{Q}_{\mathrm{r}}$. This implies that the SWAT model sufficiently replicated the hydrology of the study area, and can be applied in Australian conditions. In general, the SWAT model overestimated flows in dry years, and underestimated in wet years.

Keywords: $\quad$ Streamflow, Water quality, SWAT, Yarra River catchment, Australia 


\section{INTRODUCTION}

Excessive loadings of diffuse (nonpoint) pollution from agricultural activities cause critical social, economical and environmental problems such as eutrophication in rivers and creeks, and are a major concern to water resource managers. Agricultural production systems are complex and variable, comprising a large number of subsystems that interact dynamically over time. Because of adverse climatic and geographic conditions, and space limitations, it is a challenge in many locations to maintain reasonable agricultural production levels without overusing natural resources. This condition creates the need for improved agricultural production systems i.e. Best Management Practices (BMPs) that embrace sustainable use of resources and pollution control of surrounding water systems. However, it is difficult to identify the most effective BMP or integrated effects of several BMPs before implementation. Catchment-scale hydrologic and diffuse source pollution models simulating and simplifying the complex processes of a catchment are useful analysis tools to understand the problems and find solutions through simulation of BMPs for particular catchments and agronomic settings (Borah and Bera, 2004).

A wide range of models exists for use in simulating sediment and associated pollutant transport. In general, models fall into three main categories (Merritt et al., 2003), depending on the physical processes simulated by the model: (i) empirical or statistical models such as LOADEST (Runkel et al., 2004); (ii) conceptual models such as CatchMODS (Newham et al., 2004); and (iii) physics-based models such as SWAT (Arnold et al., 1998). Another way to view the range of models is the way in which they consider processes and parameters to be lumped or distributed. Based on temporal scale, a model could be event-based or long-term continuous simulation model. Thorsen et al. (2001) pointed out that the predictive capability of empirical and lumped conceptual models with regards to assessing the impacts of alternative agricultural practices is questionable, due to the semi-empirical nature of the process description. Compared to the lumped conceptual models, continuous physics-based distributed models are better suited for the accurate simulation of spatial and temporal patterns in surface runoff, sediment, chemicals, and nutrients and their associated transport pathways (Borah and Bera, 2003). However, these models require high expertise and extensive data in all stages from model development to model evaluation. Because of these high data requirement and processing, the applications of these models are limited in many data-poor catchments.

In general, Australian catchments are data-rich in terms of hydroclimatic data, but data-poor especially for water quality and land use management data compared to Europe or America. Information on erosion, soil properties or spatially referenced land use and ecosystem data is also relatively sparse, complicating the development of water quality models. Letcher et al. (1999) pointed out that physics-based models are not particularly appropriate across most Australian catchments for lack of sufficient data for model development and evaluation. Therefore, traditionally used water quality models in Australia such as "Source Catchments" (eWater-CRC, 2010), CatchMODS (Newham et al., 2004) are lumped/semi-distributed conceptual models. Within these models, nutrients sub-models are mainly generation rate-based (empirical), and do not have instream nutrient processing. Moreover, the effects of potential management practices in agricultural areas, e.g. fertilizer application rates cannot be simulated with these models (Newham and Drewry, 2006).

With the advent of computationally efficient computers and GIS software, physics-based models are increasingly being called upon in data-poor regions (Borah and Bera, 2003). The extensive input data for physics-based models are often generated from GIS and regional or local surveys. However, very limited applications of these models have been found in Australian catchments. Baginska et al. (2003) examined applicability and predictive capability of the AnnAGNPS (Bingner and Theurer, 2001) model in the Currency Creek catchment, Sydney (Australia). The model showed a poor performance for nutrient prediction because of limited data availability for the model development and optimization. The model was optimized only for five runoff events during three years period. Similarly, Jivajirajah and Rahman (1994) applied HSPF (Bicknell et al., 1993) model in the Upper Nepean catchment, Sydney for diffuse source nutrient modeling, and reported calibration problems due to inadequate water quantity and quality data. Limited application of SWAT has been found in Australia mainly for modelling hydrology (such as Watson et al., 2003).

Currently, adoption of SWAT as a tool for predicting land use change impacts on water quality in the Yarra River catchment, Victoria (Australia) is being considered to test the applicability of SWAT model under data-poor (especially water quality and land management data) conditions of Australia. The main objective of this paper is to evaluate the hydrological behaviour of SWAT model in the agricultural part of the Yarra River catchment, Victoria (Australia) for 1990-2008 periods. The paper discusses the sources of different data types and their appropriate processing techniques required for the model setup and calibration processes which will be beneficial for model developers in applying physics-based models under Australian conditions. 


\section{MATERIALS AND METHODS}

\subsection{Study Area}

The Yarra River located in Victoria, Australia is the source of Melbourne city's high quality drinking water and supports a thrive of agricultural industries. The Yarra River catchment has an area of over $4000 \mathrm{~km}^{2}$ with 21 percent natural vegetation, 57 percent agricultural and 22 percent urban land cover. The catchment has three distinct segments, namely: Upper, Middle and Lower Yarra segments based on land use activities as shown in Figure 1. The Upper Yarra segment consists of mainly dense and extensive forested area. The Middle Yarra segment is mainly rural floodplains and valleys. The Lower Yarra segment is mainly urbanized floodplains, and has the poorest water quality. The annual rainfall of the Yarra River catchment varies from approximately 1,600 $\mathrm{mm}$ in the Upper Yarra to $600 \mathrm{~mm}$ in the Lower Yarra region (Das et al., 2011). Low flows occur from November to June, whereas high flows occur during other times of the year.

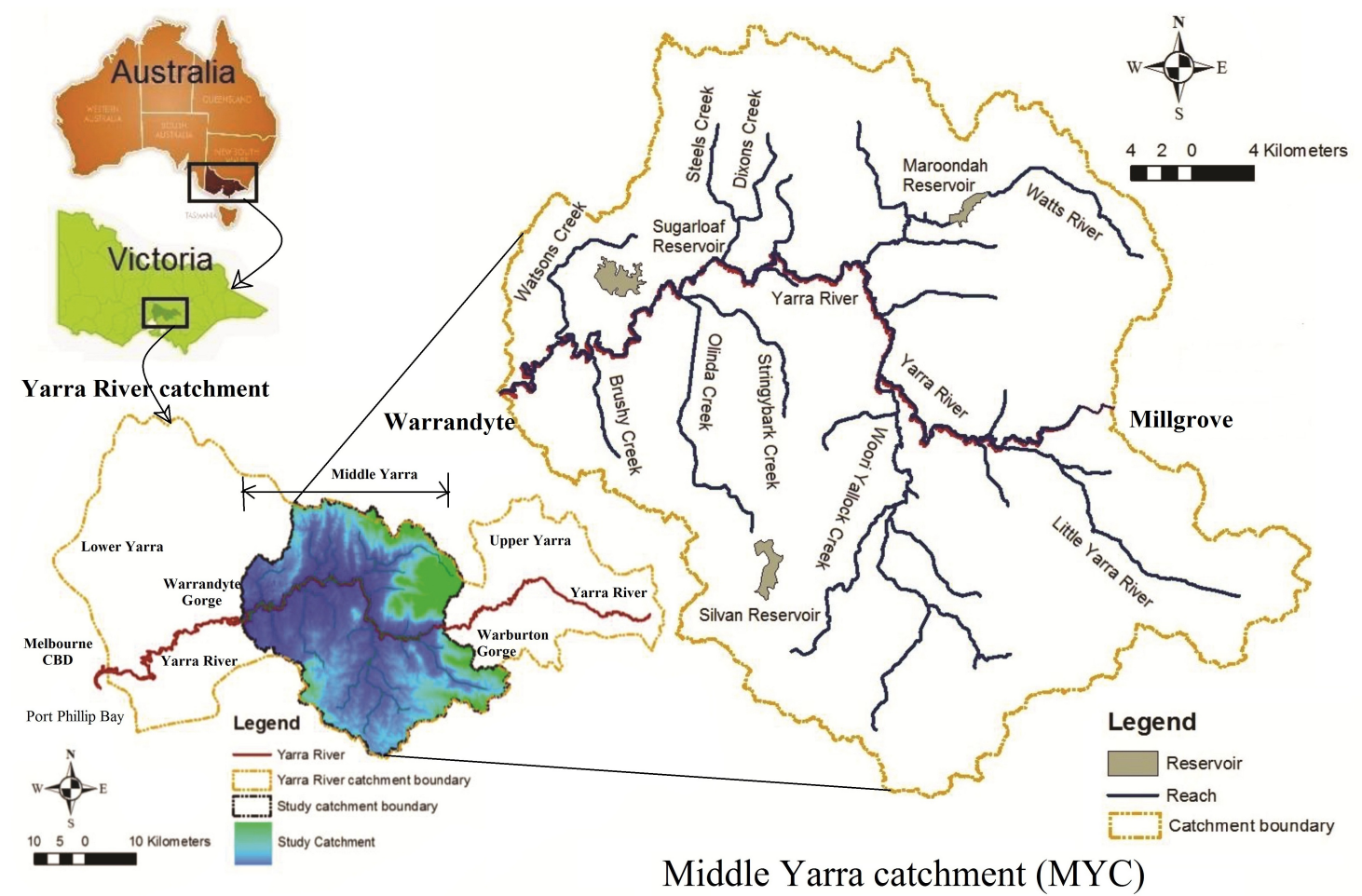

Figure 1. Location map of the Middle Yarra catchment

The Middle Yarra segment covering a total area of about $1511 \mathrm{~km}^{2}$ is selected as the case study area as shown in Figure 1, and will be referred as Middle Yarra Catchment (MYC) for rest of the paper. The Yarra River catchment is the largest generator of contaminants, both in terms of total load and load per unit area in the Port Phillip Bay region (Melbourne Water and EPA Victoria, 2009). Intensive agricultural activities from the MYC contribute a significant amount of diffuse pollutants into the river.

\subsection{SWAT Model}

This study uses the ArcSWAT interface of the SWAT2005 model (Winchell et al., 2009). The SWAT model is a non-proprietary hydrologic/water quality tool developed by the United States Department of AgricultureAgriculture Research Service (Arnold et al., 1998). The SWAT model is a continuous physics-based distributed parameter model that operates on a daily time-step. It has the capability to simulate the impact of land use management on water, sediment and agricultural-chemical yields in complex catchments with varying soils, land use and management conditions over long periods of time. The ability to simulate instream water quality dynamics on the basis of routines developed for the QUAL2E model is a definite strength of SWAT (Gassman et al., 2007). Moreover, SWAT has an embedded powerful sensitivity, and autocalibration and uncertainty analysis tool. Based on a review of eleven widely used diffuse pollution models, Borah and Bera (2004) recommended that SWAT is a promising model for long-term continuous simulations in predominantly agricultural catchments. A comprehensive review of SWAT including historic developments and applications can be found in Gassman et al. (2007). 
Das et al., Development of a SWAT model in the Yarra River catchment

\subsection{Data Collection and Processing}

All necessary data types and their respective sources for the SWAT model setup and calibration are shown in Table 1. The digital input maps and monitoring stations for climate, streamflow and water quality data are shown in Figure 2.

Table 1. Data sources for the SWAT model

\begin{tabular}{ll}
\hline Data & Source \\
\hline $\begin{array}{l}\text { Digital Elevation Model } \\
\text { (DEM) }\end{array}$ & $\begin{array}{l}\text { ASTER 30m GDEM, jointly developed by The Ministry of Economy, Trade, and Industry (METI) of } \\
\text { Japan and the United States National Aeronautics and Space Administration (NASA), } \\
\text { (http://asterweb.jpl.nasa.gov/gdem-wist.asp) }\end{array}$ \\
\hline Soil & $\begin{array}{l}\text { Atlas of Australian Soils from Australian Soil Resource Information System (ASRIS) developed by } \\
\text { CSIRO and Department of Agriculture, Fisheries and Forestry (DAFF) (http://www.asris.csiro.au) }\end{array}$ \\
\hline Land use & 50m grid raster data for the period of 1997 to May 2006 collected from Australian Bureau of \\
& Agricultural and Resource Economics and Sciences (ABARES) (http://adl.brs.gov.au/landuse) \\
\hline Climate & $\begin{array}{l}\text { 16 rainfall and 4 temperature (max and min), solar radiation, wind speed and relative humidity stations } \\
\text { data from SILO climate database (http://www.longpaddock.qld.gov.au/silo) and Bureau of }\end{array}$ \\
& Meteorology (BoM) (http://www.bom.gov.au/climate/data/). \\
\hline Land use management & $\begin{array}{l}\text { Manure, fertilizer type and application rate, tillage practices, cropping seasons, and irrigation rate from } \\
\text { Australian Bureau of Statistics (http://www.abs.gov.au), Department of Environment and Primary } \\
\text { Industries (http://www.depi.vic.gov.au/) and Melbourne Water (http://www.melbournewater.com.au/) }\end{array}$ \\
\hline $\begin{array}{l}\text { Streamflow and water } \\
\text { quality }\end{array}$ & $\begin{array}{l}\text { Daily streamflow and monthly water quality grab sample data for two stations at Warrandyte (outlet of } \\
\text { the MYC) and Millgrove from Melbourne Water (http://www.melbournewater.com.au/) }\end{array}$ \\
\hline
\end{tabular}

Soil classification for the Atlas of Australian Soils is based on the Factual Key. The Factual Key (Northcote, 1979) was the most widely used soil classification scheme prior to the Australian Soil Classification (ASC) (Isbell, 2002). The soil names as shown in the map (Figure 2b) are as per the ASC system with dominant Principal Profile Form (PPF) in brackets as per the Factual Key. The dominant soil types in the catchment are Sodosol (about 54\%) and Dermosol (about 35\%). The soil properties (depth of soil layer, texture, moist bulk density, available water capacity, organic carbon content, saturated hydraulic conductivity, moist soil albedo, USLE equation soil erodibility factor and soil hydrologic group) were available for two layers of the soil.
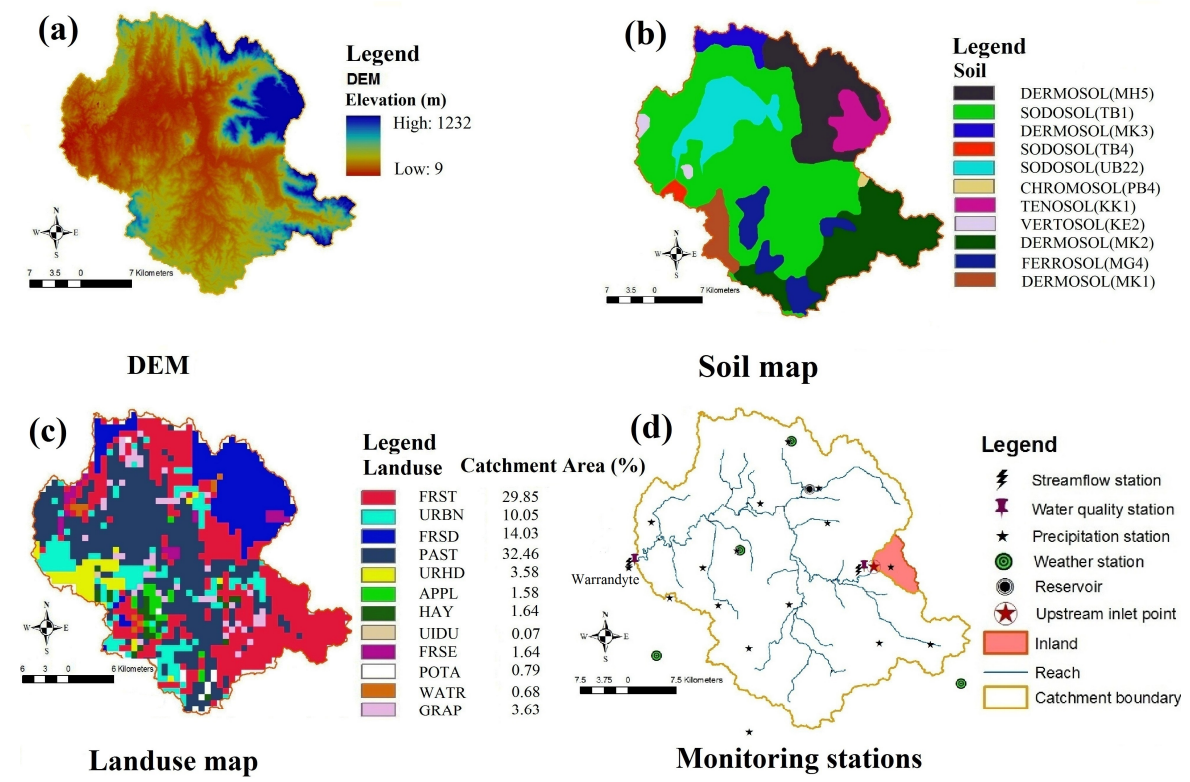

Figure 2. Spatial input maps and monitoring stations for SWAT model in the MYC

Since SWAT has pre-defined land use types through which it creates link with land use map, the land use classes generated for the MYC were re-classified and made compatible with the requirements of the SWAT model. Figure 2c shows the detailed land use types in the MYC with pasture covering around $32 \%$ of the total area. All climate data were collected for 1980-2008 period. Figure 3 shows that there is an abrupt drop in annual average rainfall (from $1140 \mathrm{~mm}$ to $922 \mathrm{~mm}$ ) from 1997 onwards indicating one of the most severe drought events in the MYC.

Baseflow $\left(Q_{b f}\right)$ and surface runoff $\left(Q_{r}\right)$ also need to be calibrated along with the total flow $\left(Q_{t}\right)$ to represent surface and subsurface hydrological processes accurately; otherwise the model may cause wrong estimates of 
the diffuse pollution loads. In this study, baseflow was separated using automated digital filter based software "Baseflow Filter Program" (USDA-ARS, 1999) which compares well to measured results and other techniques (Arnold et al., 1995). Baseflow separation showed that about $75 \%$ of the total flow was contributed by the baseflow in the MYC. Monthly grab sample data of Total Nitrogen (TN), Total Phosphorus (TP) and Total Suspended Solid (TSS) were available for 1998-2008 period. Streamflow and water quality data were also collected from the station at Millgrove to add streamflow and constituent loads from the Upper Yarra into the MYC through the "upstream inlet point" (Figure 2d) in the SWAT model. Since the correlations between concentrations of TN, TP, TSS and streamflow (TN: 0.71-0.76, TP: 0.58-0.76, and TSS: $0.65-0.76)$ were high and statistically significant $(\mathrm{p}<0.01)$, regression based model LOADEST (Runkel et al., 2004) was used to estimate constituent loads (required for the SWAT model water quality calibration) from the grab sample data (Das et al., 2011). Coefficients of determination $\left(\mathrm{R}^{2}\right)$ for the regression models in LOADEST were greater than 0.86 for TN, TP and TSS.

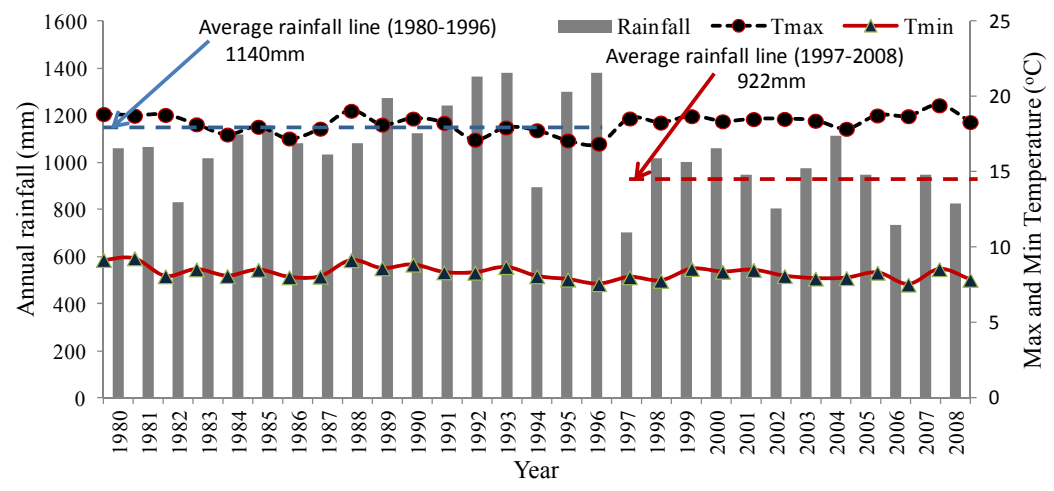

Figure 3. Annual rainfall and temperature (max and min) in the MYC

\subsection{SWAT Model Setup and Calibration}

All necessary spatial datasets and database input files for the model were organized and assembled following the guidelines of ArcSWAT interface of the SWAT 2005 version (Winchell et al., 2009). The MYC was delineated into 51 sub-catchments and 431 hydrological response units, which are unique combinations of land use, soil type and slope. The main methods used in modeling the hydrologic processes were curve number $(\mathrm{CN})$ method for runoff estimating, Penman-Monteith method for PET and Muskingum method for channel routing considering in-stream nutrient transformations.

SWAT embedded sensitivity and auto-calibration tool was used for sensitivity analysis and calibration of the model at Warrandyte (MYC outlet). 1990-2002 (contain wet and dry years) and 2003-2008 (contain only dry years) periods were considered as calibration and validation period respectively for streamflow with a 10 years "warmup" period in the SWAT model. The LH-OAT (Latin-Hypercube and One-factor-At-a-Time) sensitivity analysis method was applied for all 26 SWAT streamflow parameters. Based on the sensitivity results, the ParaSol (SCE-UA) auto-calibration was performed on 14 most sensitive streamflow parameters. For runoff and baseflow calibration, manual tuning was done to the runoff and baseflow related parameters.

\section{RESULTS AND DISCUSSION}

All data for the SWAT model were collected from local authorities in Australia except DEM. The data were processed with ArcGIS interface and other appropriate techniques. Water quality and land use management data were most sparse. In most cases, land use management data were available at larger spatial scale (Melbourne Statistical Division or Port Phillip and Western Port Region) than the MYC. The LOADEST models performed well in estimating constituent loads $\left(\mathrm{R}^{2}>0.85\right)$ from water quality grab samples.

The SWAT model streamflow calibration and validation results were evaluated based on the guidelines provided by Moriasi et al. (2007), and using the evaluation statistics of Coefficient of Determination $\left(\mathrm{R}^{2}\right)$, Nash-Sutcliffe Efficiency (NSE), Percent Bias (PBIAS) and RMSE-observations standard deviation ratio (RSR) as shown in Table 2. The scatter plots of $Q_{t}$ in calibration and validation periods are shown in Figure 4. The model performance statistics showed that the SWAT model performed very well for $Q_{t}$, well for $Q_{b f}$ and satisfactory for $\mathrm{Q}_{\mathrm{r}}$. The model under predicted $\mathrm{Q}_{\mathrm{t}}$ and $\mathrm{Q}_{\mathrm{bf}}$ in the calibration period, but over predicted in the validation period. However, the model under predicted $\mathrm{Q}_{\mathrm{r}}$ in both periods. This means SWAT model under predicted flows in wet years, but over predicted in dry years in the MYC. Watson et al. (2003) also found similar result with SWAT in the Woady Yaloak River catchment in Victoria, Australia. Moreover, the 
very good agreement for monthly and annual $\mathrm{Q}_{\mathrm{t}}, \mathrm{Q}_{\mathrm{bf}}$ and $\mathrm{Q}_{\mathrm{r}}$ indicates that the model would be capable of capturing other water quality related catchment processes such as erosion with the hydrology of the MYC.

Table 2. Streamflow calibration (1990-2002) and validation (2003-2008) statistics

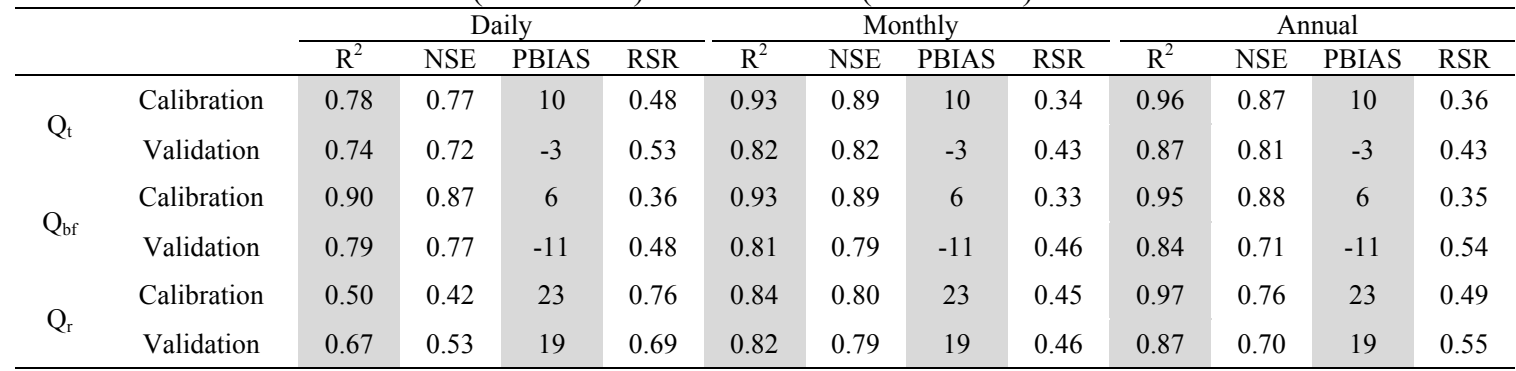

Positive and negative PBIAS values mean under prediction and over prediction respectively in percent.

Monthly simulations are satisfactory if NSE $>0.50$ and $\mathrm{RSR} \leq 0.70$, and if $\mathrm{PBIAS} \pm 25 \%$ for streamflow as per Moriasi et al. (2007).
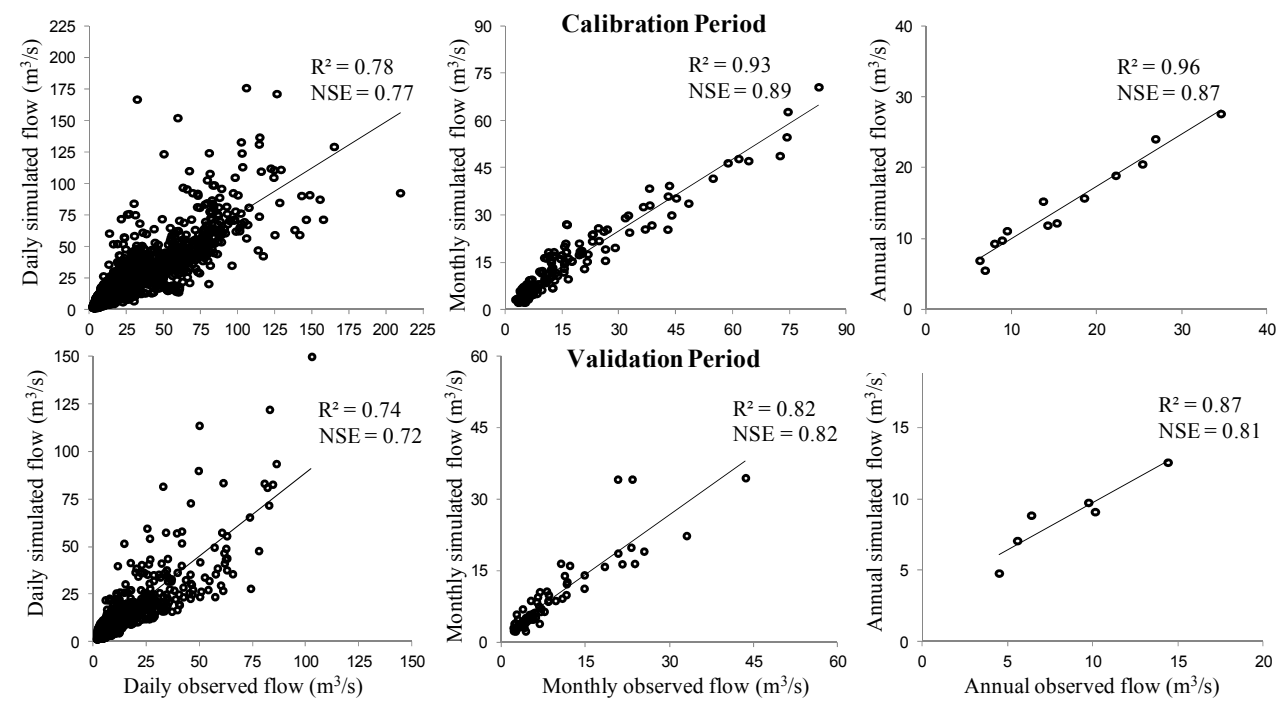

Figure 4. Observed and simulated total flow $\left(Q_{t}\right)$ during calibration and validation period in the MYC

\section{CONCLUSIONS}

The setup and evaluation of a complex physics-based model SWAT in the data-poor environment of the Yarra River catchment, Victoria (Australia) is discussed in this paper. All necessary data were collected from local authorities in Australia except DEM. In general, water quality and land use management data were most sparse. The climate in the study area was very dry from 1997 onwards which affected the streamflow calibration processes. The data required for the SWAT model were processed with ArcGIS interface and other appropriate techniques. The evaluation statistics for total flow, baseflow and runoff in the calibration and validation period showed that the SWAT model sufficiently replicated the hydrology of the study area, and would be capable of capturing other water quality related catchment processes. This implies that SWAT model can be applied in Australian conditions.

\section{ACKNOWLEDGMENTS}

The authors wish to thank the Australian organizations: Melbourne Water, CSIRO, DAFF, ABARES, SILO climate database, BoM, DEPI, and ABS; U.S. Department of Agriculture-Agriculture Research Service; U.S. Bureau of Reclamation; U.S. Geological Survey and NASA-Japan government for providing data and tools.

\section{REFERENCES}

Arnold, J.G., Allen, P.M., Muttiah, R., and Bernhardt, G. (1995). Automated base flow separation and recession analysis techniques. Ground Water, 33(6), 1010-1018.

Arnold, J.G., Srinivasan, R., Muttiah, R.S., and Williams, J.R. (1998). Large area hydrologic modeling and assessment part I: model development. Journal of the American Water Resources Association, 34(1), 7389. 
Das et al., Development of a SWAT model in the Yarra River catchment

Baginska, B., Milne-Home, W., and Cornish, P.S. (2003). Modelling nutrient transport in Currency Creek, NSW with AnnAGNPS and PEST. Environmental Modelling \& Software, 18(8), 801-818.

Bartley, R., Speirs, W.J., Ellis, T.W., and Waters, D.K. (2012). A review of sediment and nutrient concentration data from Australia for use in catchment water quality models. Marine pollution bulletin, 65(4), 101-116.

Bicknell, B.R., Imhoff, J.C., Kittle, Jr J.L., Donigian, Jr A.S., and Johanson, R.C. (1993). Hydrological Simulation Program-FORTRAN (HSPF) User's Manual for Release 10, Report No. EPA/600/R-93/176, Environmental Research Laboratory, USEPA, Athens, GA.

Bingner, R.L., and Theurer, F.D. (2001). AnnAGNPS: estimating sediment yield by particle size for sheet and rill erosion. In Seventh Interagency Sedimentation Conference, Reno, NV, pp. 1-7.

Borah, D.K., and Bera, M. (2003). Watershed-scale hydrologic and nonpoint-source pollution models: review of mathematical bases. Transactions of the ASAE, 46(6), 1553-1566.

Borah, D.K. and Bera, M. (2004). Watershed-scale hydrologic and nonpoint-source pollution models: review of applications. Transactions of the ASAE, 47(3), 789-803.

Das, S.K., Ng, A.W.M., and Perera, B.J.C. (2011). Assessment of nutrient and sediment loads in the Yarra River catchment, In F. Chan, D. Marinova and R.S. Anderssen (eds), 19th International Congress on Modelling and Simulation (MODSIM), Perth, Australia, pp. 3490-3496.

eWater-CRC (2010). Source Catchments Scientific Reference Guide, eWater Cooperative Research Centre, Canberra.

Gassman, P.W., Reyes, M.R., Green, C.H., and Arnold, J.G. (2007). The Soil and Water Assessment Tool: historical development, applications, and future research directions. Transactions of the ASABE, 50(4), 1211-1250.

Isbell R. (2002). The Australian Soil Classification, Revised edn, CSIRO, Melbourne, Australia.

Jivajirajah, J.T., and Rahman, M. (1994). Diffuse source nutrient modelling of the Upper Nepean River system, In Water Down Under 94: Surface Hydrology and Water Resources Papers; Preprints of Papers, Barton, ACT, pp. 397-402.

Letcher, R.A., Jakeman, A.J., Merritt, W.S., McKee, L.J., Eyre, B.D., and Baginska, B. (1999). Review of Techniques to Estimate Catchment Exports, NSW Environmental Protection Authority.

Melbourne Water and EPA Victoria (2009). Better Bays and Waterways - A Water Quality Improvement Plan for the Port Phillip and Westernport Region, Melbourne, Australia.

Merritt, W.S., Letcher, R.A., and Jakeman, A.J. (2003). A review of erosion and sediment transport models. Environmental Modelling \& Software, 18(8), 761-799.

Moriasi, D.N., Arnold, J.G., Van Liew, M.W., Bingner, R.L., Harmel, R.D., and Veith, T.L. (2007). Model evaluation guidelines for systematic quantification of accuracy in watershed simulations. Transactions of the $A S A B E, 50(3), 885-900$.

Newham, L.T.H., and Drewry, J.J. (2006). Modelling Catchment Scale Nutrient Generation, Technical Report 28/05, National River Contaminants Program of Land and Water Australia, CSIRO Land and Water, Canberra.

Newham, L.T.H., Letcher, R.A., Jakeman, A.J. and Kobayashi, T. (2004). A framework for integrated hydrologic, sediment and nutrient export modelling for catchment-scale management. Environmental Modelling \& Software, 19(11), 1029-1038.

Northcote, K.H. (1979). A Factual Key for the Recognition of Australian Soils, 4th edn, Rellim Technical Publishers, Glenside, SA.

Runkel, R.L. Crawford, C.G., and Cohn, T.A. (2004). Load Estimator (LOADEST): A FORTRAN program for estimating constituent loads in streams and rivers. In: Techniques and Methods Book 4, Chapter 5, pp.69. US Department of the Interior, US Geological Survey, Reston, Virginia.

Thorsen, M., Refsgaard, J.C., Hansen, S., Pebesma, E., Jensen, J.B., and Kleeschulte, S. (2001). Assessment of uncertainty in simulation of nitrate leaching to aquifers at catchment scale. Journal of Hydrology, 242(3), 210-227.

USDA-ARS (1999) U.S. Department of Agriculture-Agricultural Research Service, Soil and Water Assessment Tool, SWAT: Baseflow Filter Program. http://swatmodel.tamu.edu/software/baseflow-filterprogram (accessed 15 May 2010)

Watson, B., Ghafouri, M., and Selvalingam, S. (2003), Application of SWAT to model the water balance of the Woady Yaloak River catchment, Australia, In R. Srinivasan, J. Jacobs and R. Jensen (eds), SWAT 2003: 2nd International SWAT Conference, Temple, Texas, pp. 94-110.

Winchell, M., Srinivasan, R., Di Luzio, M., and Arnold, J.G. (2009). ArcSWAT 2.3.4 Interface for SWAT2005, User's Guide, Grassland, Soil and Water Research Laboratory, Temple, TX. 